\title{
Prevalence and Correlates of Musculoskeletal Pain in Adults with Type 2 Diabetes in Populations with Low-Risk of Obesity: A Cross- Sectional Study
}

\author{
Adedapo W Awotidebe ${ }^{*}$, Auwalu Shehu'
}

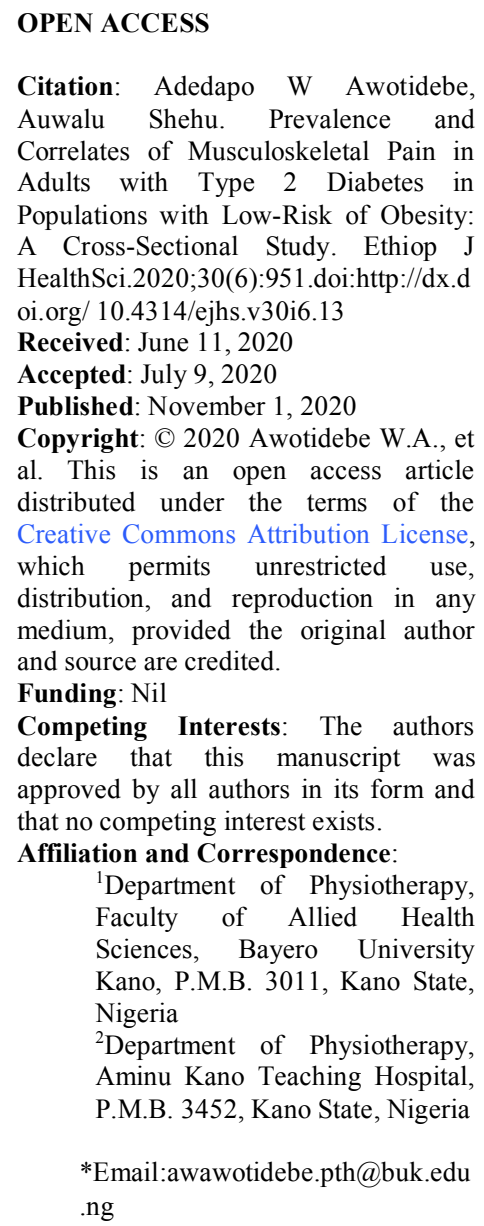

\begin{abstract}
BACKGROUND: There are few data concerning the prevalence and predictors of musculoskeletal pain among adults with type 2 diabetes in population with low-risk of obesity. Our objective was to describe the point prevalence and factors associated with increased risk of musculoskeletal pain in this population.

METHODS: A cross-sectional data of 200 adults with type 2 diabetes, aged $\geq 18$ years who were attending two tertiary hospitals were examined. Musculoskeletal pain and physical activity were collected with Nordic Musculoskeletal Questionnaire (NMQ) and International Physical Activity Questionnaire (IPAQ$S F)$ respectively. We used logistic regression to examine the risks associated with musculoskeletal pain.

RESULTS: The point prevalence of musculoskeletal pain was 72.7\% and similar between men (72.3\%) and women (73.1\%). In the last 7days, advancing age (odds ratio=1.09;95\%CI:1.02-1.16) and comorbidity (odds ratio=3.0;95\%CI:1.07-8.39) were risk factors associated with musculoskeletal pain. In the last 12 months, only comorbidity (odds ratio=5.57;95\%CI:1.62-19.17) was a risk factor for increasing musculoskeletal pain. However, a unit increase in physical activity level (odds ratio $=0.06 ; 95 \%$ CI:0.008-0.51) was associated with decreased odds of musculoskeletal pain.
\end{abstract}

CONCLUSIONS: The prevalence of musculoskeletal pain was high and physical activity was associated with a decreased risk thereof. A further research should be evaluated on the influence of physical activity on musculoskeletal pain.

KEYWORDS: Prevalence, Musculoskeletal Pain, Type 2 Diabetes, Obesity, Physical Activity.

\section{INTRODUCTION}

Type 2 diabetes mellitus is one of the leading causes of mortality globally (1), a development that has contributed to the socioeconomic burden and unfavourable economic indices in both developed and developing nations (2). People with type 2 diabetes have a higher prevalence of musculoskeletal pain and its manifestation in this population accounts for a marked increase in institutionalization and hospital visits (3). In two cross-sectional 
studies, the prevalence of musculoskeletal pain in adults above 18 years with type 2 diabetes ranged from $46.5 \%$ to $82 \% \quad(4,5)$. The prevalence of musculoskeletal pain increases with age and is higher in women (6). The mechanism of musculoskeletal pain in adults with type 2 diabetes is less clear; however, several factors have been observed to exacerbate the propensity for musculoskeletal pain. These include neuropathy (7) vascular insufficiencies (8), vitamin D deficiency (9), decreased insulinlike growth factors (IGF-1) (10), sedentary behaviours (11), reduced dietary intake (12) and obesity (13). Musculoskeletal pain is associated with decreased physical function and quality of life (6). Therefore, improving the physical activity (PA) level of patients with type 2 diabetes is crucial to promoting physical function and quality of life. Guidelines for physical activity in this population recommend moderate-intensity exercise of at least 150 minutes per week. This threshold is associated with improved glycaemic control and insulin sensitivity (14). Apart from aerobic exercise, it has also been observed that resistance training reduces the prevalence of hyperglycaemia in patients with type 2 diabetes (14).

However, there are concerns that inherited genetic susceptibility, behavioural risk variations (e.g. obesity and sedentary lifestyle), and ethnic differences are central to defective insulin secretion and insulin resistance (15). This phenomenon underscores the variations in vascular complications and risk factors associated with type 2 diabetes (16). For example, the effect of environmental factors (obesity) and difference in genetic origin are some of the reasons why the prevalence of type 2 diabetes is low in African countries compared with Western countries (17). Consequently, there is a paucity of studies in African populations on the prevalence of musculoskeletal pain and its risk factors in populations with low risk of obesity. Studies in African populations are thus needed. The aim of this study therefore was to determine the point prevalence of musculoskeletal pain and its risk factors in adults with type 2 diabetes in Northern Nigeria. We hypothesized that the prevalence of musculoskeletal pain in this setting will be lower than what was reported elsewhere.

\section{MATERIALS and METHODS}

This was a cross-sectional hospital-based study was conducted on adults with type 2 diabetes, aged 18 or older who were attending the endocrinology clinic of two tertiary hospitals in Kano metropolis, Nigeria. We used the diabetes registers, which included information on diagnosis, co-existing conditions, treatment and demographic characteristics, to recruit participants into the study. The participants were recruited consecutively during routine treatment visits. However, patients diagnosed with type 2 diabetes but either had a physical disability and/or a diabetic foot were excluded from the study.

The sample size for this study was estimated using single proportion formula (18) taking previous prevalence of musculoskeletal pain in this population, $82.6 \%(5)$ and a precision error of $5 \%$, we used a priori sample size parameters $(\mathrm{Z}=1.96 ; \mathrm{P}=0.826 ; \mathrm{d}=0.05)$ to estimate an appropriate sample size of 220.

Data collection, variables and sources of data: Data were collected between August 01 and November 31, 2017. Demographic variables obtained include age, gender, level of education, disease duration and co-existing conditions. Body weight and height were measured according to the standards of the International Society for the Advancement of Kinanthropometry (ISAK) (19). We collapsed both "Obesity" (BMI $\geq 30 \mathrm{~kg} / \mathrm{m}^{2}$ ) and "Overweight" (BMI 25-29.99 kg/m²) into one category "Obesity" in order not to violate the assumptions of chi-square concerning the minimum expected cell frequency. Underweight was defined as BMI $<18.5 \mathrm{~kg} / \mathrm{m}^{2}$ and "Normal" weight as BMI of $18.5-24.99 \mathrm{~kg} / \mathrm{m}^{2}$. The Standardized Nordic Musculoskeletal Questionnaire (20) was used to assess the presence of musculoskeletal pain in nine major body regions (neck, shoulders, upper back, lower back, elbows, wrists, thighs, knees and ankles) in the 7 days (acute pain) and 12 months (chronic pain) before the study. The presence of musculoskeletal pain in at least one body region was categorized as (Yes pain: 1) and no pain in 
any body region was categorized as 0 (No pain: 0 ). The dichotomous variable (Yes pain: 1; No pain: 0) was used to estimate point prevalence of musculoskeletal pain in the last 12 months. The International Physical Activity Questionnaireshort version (IPAQ-Short Form) (21) was used to assess the frequency, intensity, duration and type of seven-day recall of total physical activity. The total PA was defined as "Low PA" (<3 MET, Metabolic Equivalent Task), "Moderate PA" (3-6 MET) and "Vigorous PA" ( $>6$ MET) (22). One MET is defined as the energy expended (or amount of oxygen consumed) at rest and is roughly equal to $3.5 \mathrm{ml}$ of $\mathrm{O}_{2}$ per kilogram body weight multiplied by a minute in adults.

Ethical approval: Ethical approval was obtained from the Aminu Kano Teaching Hospital Research Ethics Committee (AKTH/MAC/SUB/12A/P-3/VI/2110) and the ethical protocols of the Declaration of Helsinki (1967) including the ethical principles of informed consent, voluntary participation and withdrawal, privacy and confidentiality, were followed to ensure wellbeing, safety and protection of study participants (23).

Data analysis and statistics: Descriptive statistical techniques in the form of tables, charts and percentages were used to present the prevalence and patterns of musculoskeletal pain in the last 12 months. Inferential statistics of Chi-square test $\left(\chi^{2}\right)$ for independence (with Yates Continuity Correction) were used to determine the association between the presence of musculoskeletal pain $(1=$ Yes; $0=$ No pain $)$ and participants' characteristics (sex, age, education, presence of co-existing condition,
BMI, and PA). Multivariate logistic regression (stepwise forward selection method) was used to determine the contribution of each of age, sex, education, co-morbidity, disease duration, body mass index and physical activity to the presence of musculoskeletal pain. Assumptions for logistic regression were checked for multicollinerity (Cook's distance), model's fit (Omnibus test; Hosmer and Lemeshow test), and potential outliers were checked. The data were analysed using the Statistical Package for Social Science (SPSS) version 22 and significance level (alpha level) was set at 0.05 .

\section{RESULTS}

Characteristics of the study population: A total of 198 adults with type 2 diabetes, with a mean age of 48.3 years were examined (Table 1). The majority of the participants were females (52.5\%), had informal education (47\%) and had comorbidity $(40.9 \%)$. Their mean disease duration was $3.24 \pm$ SD 2.78 years; mean BMI was $25.85 \pm \mathrm{SD} 4.09 \mathrm{~kg} / \mathrm{m}^{2}$ and mean total physical activity was $6.81 \pm 0.93$ MET. Overall, $42.9 \%$ had low physical activity.

Prevalence and pattern of musculoskeletal pain: The overall prevalence of musculoskeletal pain was $72.7 \%$, similar in men and women. (Figure 1). Prevalence of musculoskeletal pain increased with age, comorbidity, low education and sedentary behaviour (Figure 1). Most occurrences of musculoskeletal pain were in the upper extremities, in the head $(59.3 \%)$, neck $(59.3 \%)$ and shoulder (42.4\%) (Figure 2). The prevalence of musculoskeletal pain was least in the wrist $(18.6 \%)$ and the elbow (18.1\%). 
Table 1: Demographic and clinical characteristics and outcomes of adults with type 2 diabetes in low risk obesity populations:

\begin{tabular}{|c|c|c|c|c|}
\hline Variables & $\begin{array}{l}\text { All } \\
(n=198)\end{array}$ & $\begin{array}{l}\text { Without MSP } \\
(n=54)\end{array}$ & $\begin{array}{l}\text { With MSP } \\
(n=144)\end{array}$ & P-value \\
\hline Age, year & $48.26 \pm 10.73$ & $46.19 \pm 10.62$ & $53.58 \pm 12.31$ & 0.001 \\
\hline \multicolumn{5}{|l|}{ Sex, n (\%) } \\
\hline Male & $94(47.5)$ & $26(48.1)$ & $68(47.2)$ & \multirow[t]{2}{*}{0.907} \\
\hline Female & $104(52.5)$ & $28(51.9)$ & $76(52.8)$ & \\
\hline \multicolumn{5}{|l|}{ Education, n (\%) } \\
\hline Informal & $93(47.0)$ & $9(16.7)$ & $84(58.3)$ & \multirow{4}{*}{0.001} \\
\hline Primary & $27(13.6)$ & $9(16.7)$ & $18(12.5)$ & \\
\hline Secondary & $24(12.1)$ & $9(16.7)$ & $15(10.4)$ & \\
\hline Tertiary & $54(27.3)$ & $27(49.9)$ & $27(18.8)$ & \\
\hline \multicolumn{5}{|l|}{ Comorbidity., n (\%) } \\
\hline No & $117(59.1)$ & $44(81.5)$ & $73(50.7)$ & \multirow[t]{2}{*}{0.001} \\
\hline Yes & $81(40.9)$ & $10(18.5)$ & $71(49.3)$ & \\
\hline \multicolumn{5}{|l|}{ PA $(\%)$} \\
\hline Low & $85(42.9)$ & $10(18.5)$ & $75(52.1)$ & \multirow[t]{3}{*}{0.001} \\
\hline Moderate & $103(52)$ & $38(70.4)$ & $65(45.10$ & \\
\hline High & $10(5.1)$ & $6(11.1)$ & $4(2.8)$ & \\
\hline Duration, year & $3.24 \pm 2.78$ & $2.88 \pm 3.10$ & $4.69 \pm 3.62$ & 0.001 \\
\hline BMI (kg/m²) & $25.85 \pm 4.09$ & $25.66 \pm 3.45$ & $25.59 \pm 4.07$ & 0.910 \\
\hline Moderate PA (MET) & $5.35 \pm 1.08$ & $5.73 \pm 0.97$ & $5.12 \pm 1.10$ & 0.001 \\
\hline Vigorous PA (MET) & $6.00 \pm 1.14$ & $6.58 \pm 0.86$ & $5.75 \pm 1.17$ & 0.001 \\
\hline Total PA (MET) & $6.81 \pm 0.93$ & $7.09 \pm 1.14$ & $6.05 \pm 1.30$ & 0.001 \\
\hline
\end{tabular}

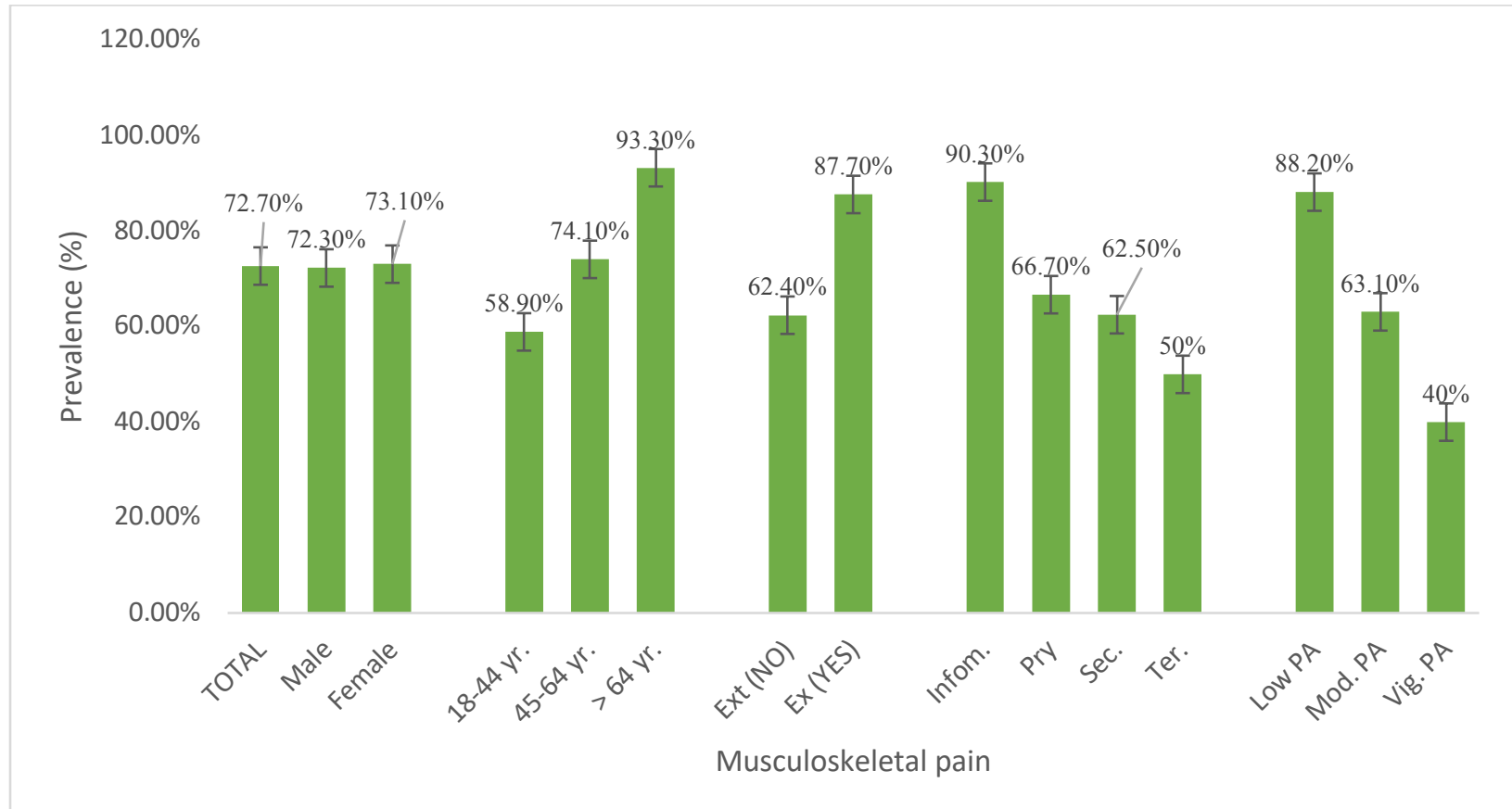

Figure 1: Prevalence of musculoskeletal pain in adults with type 2 diabetes according to gender, age, existing conditions, education and physical activity level 


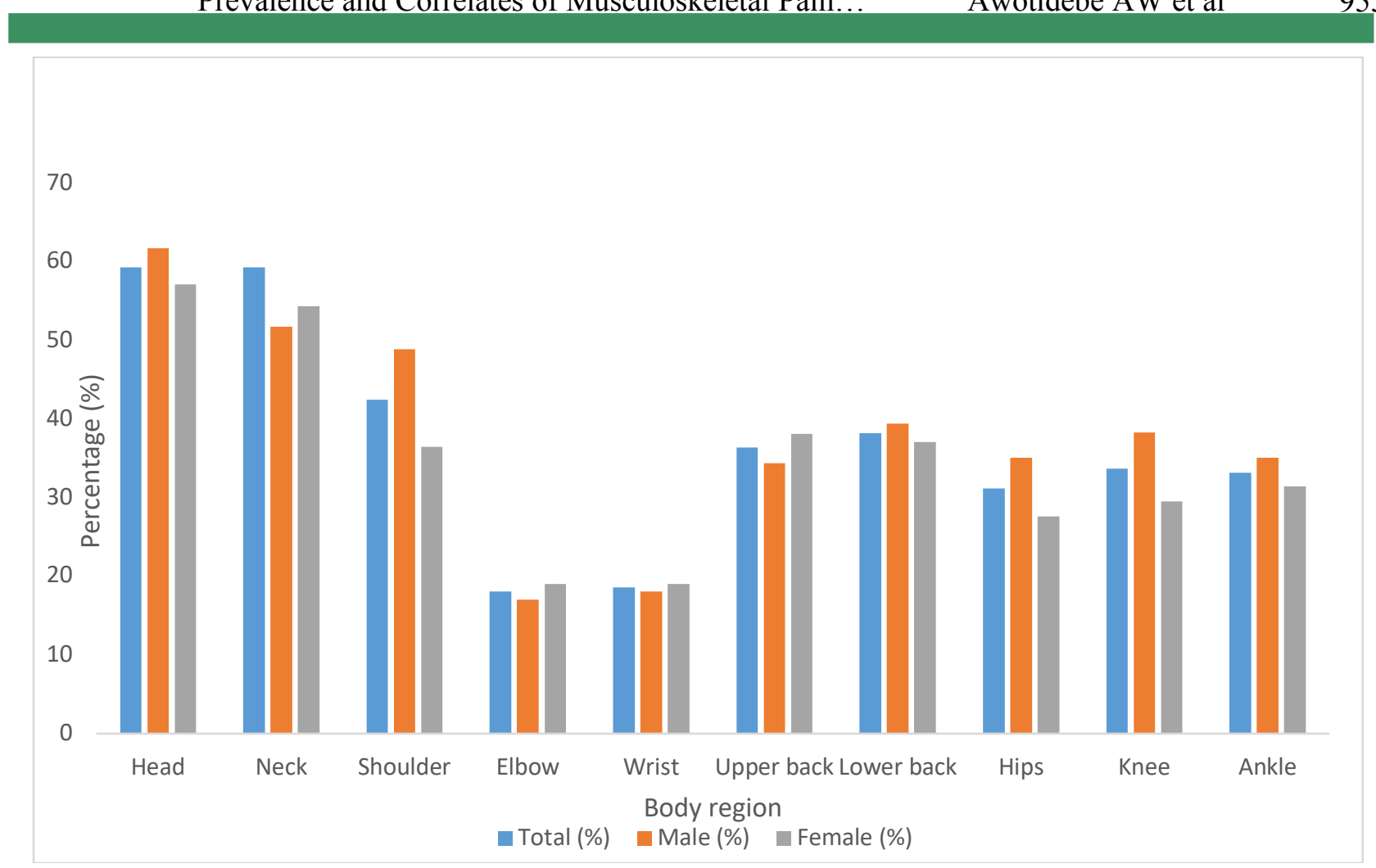

Figure 2: Pattern of musculoskeletal pain in adults with type 2 diabetes in a low-risk obesity population.

Risk factors for musculoskeletal pain: Chisquare test $\left(\chi^{2}\right)$ of independence indicated a significant association between musculoskeletal pain status and age [seven-day MSP: $\chi^{2}(2)=$ $30.70, \mathrm{p}<0.001 ; 12$-month MSP: $\chi^{2}(2)=11.91$, $\mathrm{p}<0.05$ ], education [seven-day MSP: $\chi^{2}(3)=$ 48.71, $\mathrm{p}<0.001 ; 12$-month MSP: $\chi^{2}(2)=30.34$, $\mathrm{p}<0.001$ ] and comorbidity status [seven-day MSP: $\chi^{2}(1)=30.75, \mathrm{p}<0.001 ; 12-$ month: $\chi^{2}(2)=$ 15.40, $\mathrm{p}<0.001$ ] (Table 2). Similarly, results suggested a significant association between musculoskeletal pain and physical activity status [seven-day MSP: $\chi^{2}(2)=32.07, \mathrm{p}<0.001 ; 12$ month MSP: $\left.\chi^{2}(2)=20.53, \mathrm{p}<0.001\right]$.

In the last 7 days, logistic regression analysis showed that advancing age (odds ratio $=1.09 ; 95 \% \mathrm{CI}: 1.02-1.16)$ and comorbidity (odds ratio $=3.0 ; 95 \% \mathrm{CI}: 1.07-8.39$ ) were risk factors associated with musculoskeletal pain, $\left(\chi^{2}\right.$ $(9)=38.66, p<0.001)($ Table 3$)$. The model explained $33 \%$ variance in the risk of musculoskeletal pain (Nagelkerke, $\mathrm{R}^{2}$ ) and was able to identify $68 \%$ cases accurately. The sensitivity and specificity of the model were $71 \%$ and $65 \%$ respectively. The results showed that for every 1 unit increase in age and comorbidity status, the odds of occurrence of musculoskeletal pain in the last seven days increase by 1.09 and 3.00 times respectively. However, in the last 12 months, comorbidity and physical activity level had significant influence on musculoskeletal pain, $\left(\chi^{2}(9)=32.77\right.$, $\mathrm{p}<0.001$ ), at $43 \%$ sensitivity and $86 \%$ specificity. The results showed that comorbidity increased the odds of musculoskeletal pain in the last 12 months by 6 times $(\mathrm{OR}=5.57, \mathrm{p}=$ 0.006). However, adults with high physical activity level are 4\% likely to develop musculoskeletal pain in the last 12 months. 
Table 2: Association of selected factors with musculoskeletal pain of adults with type 2 diabetes in low risk obesity populations.

\begin{tabular}{|c|c|c|c|c|c|c|}
\hline \multirow[t]{2}{*}{ Characteristics } & \multicolumn{3}{|c|}{ 7-day musculoskeletal pain } & \multicolumn{3}{|c|}{ 12-month musculoskeletal pain } \\
\hline & No Pain & Pain & $\chi^{2}$ & No Pain & Pain & $\chi^{2}$ \\
\hline \multicolumn{7}{|l|}{ Gender, n (\%) } \\
\hline Male & $35(38.9)$ & $55(61.1)$ & \multirow[t]{2}{*}{.227} & $26(27.7)$ & $68(72.3)$ & \multirow[t]{2}{*}{.014} \\
\hline Female & $37(35.6)$ & $67(64.4)$ & & $28(26.9)$ & $76(73.1)$ & \\
\hline \multicolumn{7}{|l|}{ Age, n $(\%)$} \\
\hline $18-44 y$ & $36(64.3)$ & $20(35.7)$ & \multirow{3}{*}{$30.70 * *$} & $23(41.1)$ & $33(58.9)$ & \multirow{3}{*}{$11.91 *$} \\
\hline $45-64 y$ & $34(31.2)$ & $75(68.8)$ & & $29(25.9)$ & $83(74.1)$ & \\
\hline$>64 y$ & $2(6.9)$ & $27(93.1)$ & & $2(6.7)$ & $28(93.3)$ & \\
\hline \multicolumn{7}{|l|}{ Education, $\mathrm{n}(\%)$} \\
\hline Informal & $1(12.5)$ & $77(87.5)$ & \multirow{4}{*}{$48.71 * *$} & $9(9.7)$ & $84(90.3)$ & \multirow{4}{*}{$30.34 * *$} \\
\hline Primary & $11(39.3)$ & $17(60.7)$ & & $9(33.3)$ & $18(66.7)$ & \\
\hline Secondary & $13(54.2)$ & $11(45.8)$ & & $9(37.5)$ & $15(62.5)$ & \\
\hline Tertiary & $37(68.5)$ & $17(31.5)$ & & $27(50)$ & $27(50)$ & \\
\hline \multicolumn{7}{|l|}{ Comorbidity, n (\%) } \\
\hline No & $60(53.6)$ & $52(46.4)$ & \multirow[t]{2}{*}{$30.75^{* *}$} & $44(37.6)$ & $73(62.4)$ & \multirow[t]{2}{*}{$15.40 * *$} \\
\hline Yes & $12(14.6)$ & $70(85.4)$ & & $10(12.3)$ & $71(87.7)$ & \\
\hline \multicolumn{7}{|l|}{ BMI, n (\%) } \\
\hline Underweight & $1(25)$ & $3(75)$ & \multirow{3}{*}{2.24} & $1(25)$ & $3(75)$ & \multirow{3}{*}{.177} \\
\hline Normal & $33(42.9)$ & $44(57.1)$ & & $20(25.6)$ & $58(74.4)$ & \\
\hline Overweight/obese & $36(32.7)$ & $74(67.3)$ & & $32(28.3)$ & $8(71.7)$ & \\
\hline \multicolumn{7}{|l|}{ Physical activity, $\mathrm{n}$} \\
\hline Low & $54(53.5)$ & $47(46.5)$ & \multirow{3}{*}{$32.07 * *$} & $36(36.9)$ & $65(63.1)$ & \multirow{3}{*}{$20.51 * *$} \\
\hline Moderate & $6(60)$ & $4(40)$ & & $6(60)$ & $4(40)$ & \\
\hline High & & & & & & \\
\hline
\end{tabular}

**associations significant at $\mathrm{p}<0.001$, *association significant at $\mathrm{p}<0.05$

Table 3: Results of binary logistic regression model on risk factors for musculoskeletal pain.

\begin{tabular}{|c|c|c|c|c|}
\hline \multirow[t]{2}{*}{ Characteristics } & \multicolumn{2}{|c|}{ 7-day musculoskeletal pain ${ }^{1}$} & \multicolumn{2}{|c|}{ 12-month musculoskeletal pain ${ }^{2}$} \\
\hline & Odds Ratio (95\% CI) & P Value & Odds Ratio (95\% CI) & P Value \\
\hline Age & $1.09(1.02-1.16)$ & 0.006 & $1.04(0.98-1.10)$ & 0.23 \\
\hline Gender Female & $0.80(0.34-1.87)$ & 0.60 & $0.43(0.18-1.02)$ & 0.06 \\
\hline Disease duration & $1.01(0.79-1.28)$ & 0.96 & $0.91(0.71-1.17)$ & 0.47 \\
\hline Comorbidity & $3.00(1.07-8.39)$ & 0.04 & $5.57(1.62-19.17)$ & 0.006 \\
\hline BMI Normal & $0.67(0.04-12.14)$ & 0.78 & $1.93(0.11-35.35)$ & 0.66 \\
\hline BMI overweight/obese & $0.80(0.04-14.35)$ & 0.89 & $1.18(0.07-21.14)$ & 0.91 \\
\hline Moderate PA & $2.07(0.74-5.81)$ & 0.17 & $2.84(0.93-8.69)$ & 0.07 \\
\hline Vigorous PA & $1.02(0.28-3.75)$ & 0.98 & $2.03(0.54-7.63)$ & 0.29 \\
\hline Total $_{\mathrm{PA}}$ & $0.33(0.05-2.36)$ & 0.27 & $0.06(0.008-0.51)$ & $\mathbf{0 . 0 1}$ \\
\hline \multicolumn{5}{|c|}{$\begin{array}{l}\text { 1.Omnibus } \chi^{2}(9)=38.66, p<0.001, \mathrm{R}^{2}=24.6 \%(\text { Cox \& Snell), } 32.8 \% \text { (Nagelkerke) Overall }=67.9 \%(\mathrm{SEN}= \\
71.2 \% \text {; specificity }=64.8 \%) \\
\text { 2.Omnibus } \chi^{2}(9)=32.77, \mathrm{p}<0.001, \mathrm{R}^{2}=21 \%(\text { Cox \& Snell), } 29.1 \% \text { (Nagelkerke) Overall }=71.2 \%(\mathrm{SEN}=42.6 \% \\
\text { specificity }=85.9 \%)\end{array}$} \\
\hline
\end{tabular}




\section{DISCUSSION}

This study found that the prevalence of musculoskeletal pain in adults with type 2 diabetes in populations with low risk of obesity was $(72.7 \%)$ and proportionately similar between males and females. A similar prevalence of musculoskeletal pain among adults with type 2 diabetes has been observed in Europe (6). However, in the present study, the prevalence of musculoskeletal pain reported in the primary weight-bearing joints (lower back, knee and hip) seems lower compared to Molsted et al. with a different study population (Danish). In comparison, Molsted et al. collected history of pain in the last 14 days compared to the commonly used Nordic Musculoskeletal Questionnaire, which requested history of pain in the last seven days and 12 months. In addition, Molsted et al. was conducted among the Danish populations with a high prevalence of obesity (24). The presence of obesity increased the risk of lower limb osteoarthritis (25). Furthermore, our study population consisted of Hausa-Fulani residents, who are known to have slimmer stature and lower BMI (26). It is likely that a high proportion of them would have lower BMI, and hence prevalence of musculoskeletal pain in the lower body regions may be expected to be lower. Intuitively, the lack of association of musculoskeletal pain with obesity in our study may be partly due to reduced statistical power, resulting from collapsing of 'overweight' and 'obese' items into one item. Collapsing items for statistical convenience has previously been reported to be associated with loss of statistical information (27).

It has been observed that clustering of other components of metabolic syndromes (e.g. physical inactivity) increases the risk of diabetes-induced osteoarthritis (28). Furthermore, the lack of association thereof between obesity and increased prevalence of musculoskeletal pain appears not to be fixated on increased BMI; even adults with type 2 diabetes and normal weight but sedentary lifestyle may also be at risk. Unfortunately, the risk of musculoskeletal complications for adults with type 2 diabetes and obese compared to adults with type 2 diabetes and normal weight but who were inactive was not investigated in this study. However, in this study, physical activity and high level of education were strongly associated with a decreased risk of prevalence of musculoskeletal pain in patients with type 2 diabetes. Like in previous studies, participants with higher educational levels had lower risk of type 2 diabetes mellitus (29). Regular and increasing physical activity improve glycaemic control and reduce peripheral resistance to insulin (30), which hitherto played a protective role in reducing the formation of advanced glycation end products, a precursor of musculoskeletal complications in patients with type 2 diabetes (31). In line with the recommendations of van Dijk and colleagues (14), overwhelming evidence in the literature shows that exercise interventions, which include aerobic exercise, resistance exercise, flexibility training and balance training improve insulin sensitivity, endothelial function and glucose homeostasis in patients with type 2 diabetes. Public health education on the importance of physical activity should be undertaken to mitigate the effect of AGEs in musculoskeletal complications in patients with type 2 diabetes (32). Based on the differential estimates of sensitivity and specificity for our logistic regression models, it may be easier to associate age and comorbidity to musculoskeletal pain in the last seven days in adults with type 2 diabetes. However, poor sensitivity observed $(43 \%)$ in participants who reported musculoskeletal pain in the last 12 months presents a difficult-to-diagnose condition in the long term. It is anticipated that sensitivity and specificity vary with disease spectrum and its prevalences $(33,34)$. Overall, age and comorbidity may be more sensitive to acute musculoskeletal pain than a long-standing case of musculoskeletal pain in this population.

Nevertheless, this study had several limitations. First, the study had no control group, hence attributable risk for musculoskeletal pain in this population cannot be determined. Second, since this was a hospital-based study of the prevalence of musculoskeletal pain in adults with type 2 diabetes receiving care at selected hospitals, the prevalence of musculoskeletal pain 
in this population may be exaggerated by coexistence of other diseases. Third, the study may have been underpowered to detect the influence of BMI in the logistic regression model because we collapsed 'overweight' and 'obese' into one item. In conclusion, our results show that musculoskeletal pain is highly prevalent in adults with type 2 diabetes in populations with low risk of obesity. However, the pattern of the prevalence is lower in the primary weightbearing joints. Advancing age together with comorbidity are associated with an increased risk of musculoskeletal pain in this population. The association of physical activity and tertiary educational level with the decreased odds of prevalence of musculoskeletal pain underscores the need to develop an evidence-based health education programme designed to promote physical activity in order to prevent and reduce the effect of diabetes-related musculoskeletal complications.

\section{Highlights}

- Prevalence of musculoskeletal pain in adults with type 2 diabetes in populations with low risk of obesity is high and similar between men and women.

- Prevalence of musculoskeletal pain is higher in those who were older, having other medical conditions and sedentary.

- Advancing age and comorbidity are risk factors associated with musculoskeletal pain in adults with type 2 diabetes from a low risk obesity population.

\section{ACKNOWLEDGEMENTS}

The authors would like to thank Mrs Serifat Oladokun for providing language editing service. We also thank the Tertiary Education Trust Fund (TETFund) for sponsoring the first author to present the study in a conference.

\section{REFERENCES}

1. Lozano R, Naghavi M, Foreman K, et al. Globaland regional mortality from 235 causes of death for 20 age groups in 1990 and 2010. A systematic analysis for the Global Burden of Disease Study 2010. Lancet. 2012; 380:2095-128.

2. Seuring T, Archangelidi O, Suhrcke M. The economic costs of type 2 diabetes: a global systematic review. Pharmacoeconomics. 2015;33(8):811-831.

3. Pai L, Hung C, Li S, Chen L, Chung C, and Liu H. Musculoskeletal pain in people with and without type 2 diabetes in Taiwan: a population-based, retrospective cohort study. BMC Musculoskeletal Disorder. 2015; 16: 364 .

4. Liberman O, Peleg R, Shvartzman P. Chronic pain in type 2 diabetic patients: a cross-sectional study in primary care setting. The European Journal of General Practice. 2014; 20: 260-67.

5. Douloumpakas I, Pyrpasopoulou A, Triantafyllou A, Sampanis C, Aslanidis S. Prevalence of musculoskeletal disorders in patients with type 2 diabetes mellitus: a pilot study. Hippokratia. 2007; 11: 216-218.

6. Molsted S, Tibler J, Snorgaard O. Musculoskeletal pain in patients with type 2 diabetes. Diabetes Res Clin Practice. 2012; 96:135-40.

7. Arkkila PE, Gautier JF. Musculoskeletal disorders in diabetes mellitus: an update. Best Prac Res Clin Rheumatol. 2003; 17:945-70.

8. Browne DL, McCrae FC, Shaw KM. Musculoskeletal disease in diabetes. Practical Diabetes Int. 2001; 18: 62-4.

9. Straube S, Moore A, Derry S, McQuay H. Vitamin D and chronic pain. Pain. 2009; 141: 10-13.

10. Sherif EM, Abd Al Aziz MM, Elbarbary NS, Ahmed AM. Insulin-like growth factor1 in correlation with bone mineral density among Egyptian adolescents with type 1 diabetes mellitus. Int $J$ Diabetes in Developing Countries. 2011; 31:104-12.

11. Hoff OM, Midthjell K, Zwart JA, Hagen K. The association between diabetes mellitus, glucose, and chronic musculoskeletal 
complaints: Results from the NordTrondelag Health Study. BMC. 2008; 9: 160.

12. Palacios C, Gonzalez L. Is vitamin D deficiency a major global public health problem? Journal of Steroid Biochem. Mol. Biol. 2014; 144:138-145.

13. Esteghamati A, Etemad K, Koohpayehzadeh J, Abbasi M, Meysamie A, Noshad S, et al. Trends in the prevalence of diabetes and impaired fasting glucose in association with obesity in Iran: 2005-2011. Diabetes Res Clin. Pract. 2014; 103:319-27.

14. Van Dijk JM, Tummers K, Stehouwer DA, Hartgens F, van Loon JC. Exercise therapy in Type 2 Diabetes: is daily exercise required to optimize glycemic control? Diabetes Care. 2012; 35: 948-954

15. Murea M, Ma L, Freedman BI. Genetic and environmental factors associated with type 2 diabetes and diabetic vascular complications. The Review of Diabetic Studies .2012; 9:6-22.

16. Andersson EA, Holst B, Sparso T, Grarup $\mathrm{N}$, Banasik K, Holmkvist J, Jorgensen T, Borch-Johnsen K, Egerod KL, Lauritzen T, et al. MTNR1B G24E variant associates with BMI and fasting plasma glucose in the general population in studies of 22,142 Europeans. Diabetes. 2010; 59:1539-1548.

17. Mbaya JC, Cruickshank JK, Forrester T, et al. Standardized comparison of glucose intolerance in West-Africa origin populations of rural and urban Cameroon, Jamaica, and Caribbean migrants to Britain. Diabetes Care. 1999; 22: 434-40.

18. Daniel WW. Biostatistics: a foundation for analysis in the health sciences. $7^{\text {th }}$ ed. New York: John Wiley \& Sons; 1999.

19. Stewart A, Marfell-Jones M, Olds T, De Ridder, H. 2011 International standards for anthropometric assessment. Lower Hutt, New Zealand: ISAK, 2011.Kuorinka I, Jonsson B, Kilbom A, Vinterberg H,

20. Sorensen F, Andersson G, Jorgensen K. Standardised Nordic questionnaires for the analysis of musculoskeletal symptoms. Applied Ergonomics. 1987; 18:233-237.

21. Craig CL, Marshall AL, Sjöström M, Bauman A, Booth ML, Ainsworth BE, Pratt
$\mathrm{M}$, et al. International Physical Activity Questionnaire: 12-country reliability and validity. Medicine and Science in Sports and Exercise. 2003; 35: 1381-95.

22. World Health Organization. Global Strategy on Diet, Physical Activity and Health, Available at https://www.who.int/dietphysicalactivity/ph ysical_activity intensity/en/; 2019 [accessed 4 May 2019].World Medical Association. Ethical Principles for Medical Research involving Human Subj

23. ects, Available at https://www.who.int/bulletin/archives/79\%2 84\%29373.pdf; 2019 [accessed 10 May 2019].

24. Due P, Heitmann B, Sorensen T. Prevalence of obesity in Denmark. Obesity Reviews. 2007; 8(3):187-89

25. Louati K, Vidal C, Berenbaum F, Sellam J. Association between diabetes mellitus and osteoarthritis: systematic literature review and meta-analysis. RMD Open. 2015; 1(1): e000077. https://doi.org/10.1136/rmdopen-2015$\underline{000077 .}$.

26. Zagga $\mathrm{AD}$, Anas IY. Body mass index (BMI) of adults Hausa-Fulani in Northwestern Nigeria. Sahel Medical Journal. 2007; 10: 119-122.

27. Stromberg U. Collapsing ordered outcome categories: a note of concern. American Journal of Epidemiology. 1996; 144 (4): 421-424

28. Berenbaum F. Diabetes-induced osteoarthritis: from a new paradigm to a new phenotype. Ann Rheum Dis 2011; 70: 13546.

29. Agardh E, Allebeck P, Hallqvist J, Moradi T, Sidorchuk A. Type 2 diabetes incidence and socio-economic position: a systematic review and meta-analysis. Int $J$ Epidemiol. 2011; 40: 804-18.

30. Brooks N, Layne JE, Gordon PL, Roubenoff $\mathrm{R}$, Nelson ME, Castaneda-Sceppa C. Strength training improves muscle quality and insulin sensitivity in Hispanic older adults with type 2 diabetes. Int J Med Sci. 2006; 4:19-27.

31. Magalhaes PM, Appell HJ, Duarte JA. Involvement of advanced glycation end 
products in the pathogenesis of diabetic complications: the protective role of regular physical exercise. European review of Aging and Physical Activity. 2008; 5: 17-29.

32. Dela F, Prats C, Helge JW. Exercise interventions to prevent and manage type 2diabetes: physiological mechanisms. Med Sport Sci. 2014;60:36-47.
33. Brenner H, Gefeller O. Variation of sensitivity, specificity, likelihood ratios and predictive values with disease prevalence. Stat Med. 1997; 16:981-91.

34. Leeflang MM, Bossuyt PM, Irwig L. Diagnostic test accuracy may vary with prevalence: implications for evidence-based diagnosis. J Clin Epidemiol .2009; 62:5-12. 